\title{
Meetings with doctors in the staff grades: the development of affiliate status
}

\author{
George Stein
}

For many years, doctors in the staff grades, clinical assistants and associate specialists have made a substantial contribution to the care of psychiatric patients in the NHS but their position within the NHS and the College has been largely unrecognised. This article will describe recent attempts to remedy this situation. Numerically they comprise an important group of doctors (Table 1) and have always been more important in psychiatry than in other specialities, particularly in non-teaching districts where there are fewer consultants and junior doctors.

One of the tasks of the deputy regional adviser is to assess job descriptions for staff grade posts. A second and unrelated duty is to conduct the College census. This involves gathering information from the districts in the region and compiling a list of all the psychiatrists in each grade. The first of these duties drew my attention to the needs of the non-consultant career grade doctors. But it was the second one that provided the database needed to move the position of staff grade doctors forward because for the first time the census data provided information on all the staff grade doctors in a particular region. With the help of this information staff grade doctors in the South East Thames region were contacted and our first meeting was held at Bromley Hospital in April 1993.

The meeting was attended by 27 doctors from throughout Kent and was an exciting occasion.

Table 1. Grades of doctors in the NHS in Psychiatry. Data derived from 1994 College census

\begin{tabular}{lc}
\hline Grade & $\mathbf{n}(\mathbf{( \% )}$ \\
\hline Consultants & $2895(43)$ \\
Senior registrars & $595(9)$ \\
Registrars & $782(12)$ \\
SHOs & $1159(17)$ \\
Staff grade (Clinical assistant/Associate & $1286(19)$ \\
$\quad$ Specialist (including part-time)) & \\
Total & 6717 \\
\hline
\end{tabular}

The doctors were pleased to meet each other because their jobs were generally isolated and they only knew colleagues in their own hospital group and not those in neighbouring districts. For many the most significant aspect of the meeting was being met and addressed by an official representative of the College. It was as if they had "come out of the cold", their last contact with the College having been many years ago. We had no agenda and every opportunity was given for a free-ranging discussion covering aspects of work and conditions of service. Most of the doctors painted an optimistic picture concerning their hospitals, the consultants they worked with, and the clinical work they did. Many pointed out the advantages of a job with an almost exclusive clinical input as this offered continuity of care. There was little wish to assume the lot of the committee-bound consultant or the ever-rotating junior doctor.

Most employers seemed to behave reasonably well and consultants appreciated their work, but for many doctors an annual contract was a major source of insecurity. It made it virtually impossible to enter into dispute or even dialogue with a consultant or a manager because of fear that their contract might not be renewed. Another aspect which caused anguish was exclusion from the Royal College of Psychiatrists. Most pointed out that the work they did was similar to that of junior doctors or consultants and because they make a substantial contribution to the work of the NHS (Table 1), it seemed illogical and unfair to be excluded from the main professional organisation.

We have since had four further meetings in South East Thames and have linked up with South West Thames as these two regions have now merged. Numerous topics have come up at these meetings. Annual leave seems well respected in all trusts but the same cannot be said about study leave. Some trusts were generous, according to their staff grade doctors the same study leave rights and expenses as juniors, but others granted no study leave. In some hospitals doctors in the staff grade were expected to cover 
the leave of junior doctors. Although many had been practising psychiatry on a full-time basis for more than 15 years (two of the medical associates had been acting as consultants for more than five years), none had ever attended an annual meeting of the College. Many were working in subspecialities yet none had been to a College subspeciality meeting and most were unaware of the existence of the various subspeciality sections.

A brief survey was carried out to see the type of problems that existed and which kind of journals were read by the doctors (see Appendix).

The British Journal of Psychiatry (BJP) is sent to all Members and Fellows of the College, and is probably the most important source of postgraduate education for most consultants. The Bulletin keeps members up-to-date with activities within the profession. The survey shows that almost none of the staff grade doctors took the $B J P$ or the Bulletin but many preferred to take the British Medical Journal and were members of the BMA. It may be important to ensure that any doctors practising psychiatry in the UK regularly read the $B J P$ and Bulletin to help them keep upto-date on clinical matters and informed about activities within the profession.

As yet there is no collective term to describe this group of doctors in the same way as consultant or junior doctor. In our discussions different terms were offered including Clinical Specialist (Career Grade); Career Grade (nonconsultant); Career Specialist; Clinical Specialist (non-consultant); but there was no agreement on the best collective term to describe their relationship with the College.

It had been previously possible to have some link with the College and receive notices of meetings (but not receive the journals) by paying a fee and enjoying the dubious title of 'non-member member'. But all the doctors at our meetings felt this term was insulting and not surprisingly there were few subscribers. The most favoured word for the link with the College was 'Associate' but as the College already has Associates, the College byelaws prevent the use of this term and 'Affiliate' is to be used instead.

A special problem for staff grade doctors is isolation. Many do not originate from the UK and face a problem of integration into the wider community. However, it is the isolation within the hospital service which is more worrying. Staff grade doctors and clinical assistants in one hospital may know each other well but be unaware of colleagues in a neighbouring district. By contrast, juniors will often have met each other at medical school or during a rotational training scheme. Consultants often meet at appointment committees, postgraduate meetings or know each other from medical school or their training years. The lack of an informal network of doctors in the Staff Grade, and the absence of meetings at district or regional level, is a serious disadvantage because issues that cause concern cannot be shared with colleagues.

Our discussions were presented at a Regional Advisers and Deputy Regional Advisers meeting. chaired by the President, and attended by senior officials of the College. There was widespread support for the College to open its doors to doctors in the staff grade and to offer a more formal association. The term 'Affiliate of the Royal College of Psychiatrists' has been chosen to describe this link.

Affiliates will have the same rights and privileges as members, with the exception of voting, and will receive the $B J P$ and Bulletin, and be able to join subspeciality sections and attend College meetings. Doctors at our South Thames meetings expressed disquiet at the high price of joining, $£ 94$ for registration and $£ 160$ for one year's subscription, but I hope this does not put too many off.

The first national meeting for Affiliates was held on the 12 March 1996 under the Chairmanship of the then President, Dr Fiona Caldicott. Thirty-eight doctors came from throughout the UK. Dr Caldicott welcomed the doctors and said she had been aware for many years of the importance of their work. The College was pleased to reach out to them and welcome them into the organisation. The question of subscription had been given a lot of thought and an agreement had been reached with the College treasurer that the subscription would not be raised over the next two years even though it might be raised for Members and Fellows in line with inflation. Affiliates would meet at the College together with the President and the senior officers of the College every six months.

Affiliates would also have their own representative on council. Professor Cornelius Katona for the Continuing Professional Development (CPD) Committee sought one representative (to be elected by ballot) to work on aspects of CPD for Affiliates (and this applies for doctors in the staff grade even if they did not become Affiliates).

I hope as many doctors as possible will take up the offer of becoming an Affiliate, and also that Affiliates will in time develop their own committees and political structure so that a far wider range of issues can be explored, including job descriptions, conditions of employment, study leave rights, provision for continuing medical education, pension rights and job security. In this way psychiatrists in the staff grades will have more involvement in professional rather than purely clinical matters. We wish to welcome them more properly into the profession as a 
whole by inviting them to join the Royal College of Psychiatrists.

\section{Appendix. Survey into educational and work aspects of stafi grade doctors $(n=20)$}

(1) Study leave Always granted Granted but with difficulty Never granted

(2) Educational programme in my hospital Attend regularly Occasionally Never attend

(3) Professional organisations BMA

RCPsych

(4) Journals taken at home British Medical Journal British Journal of Psychiatry

Psychiatric Bulletin

(5) Journals read in the library

$15 \%$

$30 \%$

$30 \%$

$55 \%(11)$

$10 \%$ (1 member

1 inceptor)

$55 \%$

$10 \%$ (1 member.

1 inceptor)

$10 \%$ (1 member.

1 inceptor)
British Medical Journal $\quad 35 \%$ British Journal of Psychiatry $\quad 40 \%$ Psychiatric Bulletin 5\%

Psychological Medicine 5\%

American Joumal of Psychiatry $\quad 10 \%$

(6) Members pay $\$ 143.00$ for the privilege of being a member of the College. What percentage of fee of the membership subscription do you think is appropriate for a staff grade doctor who became an 'affiliate'?

$30 \%$ (1), $40 \%$ (4), $50 \%$ (11). $60 \%$ (1), $70 \%$ (1)

(7) If some formula were devised for an associate or affiliate how much experience should a full time have before being eligible?

1 year $(5 \%), 2$ years $(5 \%), 3$ years $(25 \%), 4$ years (16\%), 5 years $(15 \%)$

(8) Would you like some sort of representation at the College?

Yes $-100 \%$

No- $-0 \%$

(9) Would you like some sort of regular meeting with the Regional Adviser or his Deputy? Yes (100\%)

George Stein, Regional Advisor South Thames (East), and Consultant. Farnborough Hospital, Farnborough Common, Orpington, Kent BR6 8ND 